\title{
ON STRONG SEMISIMPLICITIES OF SEMIGROUPS WITH ZERO
}

\author{
by \\ F. SZÁSZ (Budapest)
}

The fundamental notions of semigroups can be found in the books of A. H. Clefford and G. B. PReston [4] and of E. S. LJApin [6]. In what follows, D. REwS' [8] factor semigroups will play an important role. For semigroups various concrete radicals were discussed by J. Bosák [2], A. H. Clif: fokd [3], H. J. Hofhise [5], J. LuH [7], St. Schwarz [9], H. Seider [10], L. N. SHEVRiv [11] and the author [13]. The possibility to investigate general radicals of semigroups with zero has been shown e.g. by author [15], [16] and R. WIEGANDT [17].

Following author's [15], a class $R$ of semigroups $S$. with zero is called a radical class if the following conditions are satisfied:

(i) Every homomorphic image of a semigroup from $\mathfrak{R}$ belongs to $\mathscr{R}$.

(ii) Every semigroup $S$ contains an ideal $R(S)$ belonging to $R$ such that $R(S)$ contains every other ideal belonging to $\mathfrak{R}$, of $S$.

(iii) We have $R(S \mid R(S))=0$ for the ideal $R(S)$ defined in condition (ii). (Here and in what follows $S / T$ denotes ReEs' factor semigroups.)

This $R(S)$ is said to be the $R$-radical of $S$. If $R(S)=S$ holds, then $S$ is called an $\mathscr{R}$-radical semigroup. If $R(S)=0$ holds, then $S$ is $\mathscr{R}$-semisimple. An $\mathscr{R}$-semisimple semigroup is said to be strongly $R$-semisimple, if every homomorphic image of $S$ is $\mathcal{R}$-semisimple. The groups with zero obviously are strongly $\mathscr{R}$-semisimple for every general radical $\mathscr{R}$. By author's paper [15] for every ideal $I$ of $S$ and for every radical $\mathscr{R}$ the subsemigroup $R(I)$ is an ideal of $S$.

It is the purpose of this paper to prove that for every radical $R$, for which every $\mathscr{R}$-semisimple semigroup also is strongly $\mathscr{R}$-semisimple the mapping $\varphi: I+R(I)$, is a join-endomorphism of the lattice of all twosided ideals $I$ of the semigroup. The similar ringtheoretical result was previously discussed by author [14]. The dualization of this semigroup-theoretical result, which also generalizes some results of Robert SHULKA [12], was investigated by author [16], and the similar ringtheoretical result by S. A. Amitsur [1].

First we verify two preliminary propositions. 
Proposition 1. The mapping $\varphi: I \rightarrow R(I)$ is monotone, i.e. $I_{1} \subseteq I_{\%}$ implies $R\left(I_{1}\right) \subseteq R\left(I_{2}\right)$ for the ideals $I_{1}$ and $I_{2}$.

Proof. Assume $I_{1} \subseteq I_{2}$. Then trivially $R\left(I_{1}\right) \subseteq I_{2}$ holds. Let us consider the first isomorphism theorem (see D. REES [8]):

$$
\left(R\left(I_{1}\right) \cup R\left(I_{2}\right)\right) / R\left(I_{2}\right) \cong R\left(I_{1}\right) /\left(R\left(I_{1}\right) \cap R\left(I_{2}\right)\right) .
$$

On the left hand side of (1) we have a twosided ideal of the 2 -semisimple Rees factor semigroup $I_{2} / R\left(I_{2}\right)$ and therefore, by author's paper [15], this ideal is again $\mathscr{R}$-semisimple. But on the right hand side of (1) one has a homomorphic: image of the $\mathscr{R}$-radical semigroup $R\left(I_{1}\right)$. Thus, by condition (i) on the right. hand side of (1) stays an $\mathscr{R}$-radical semigroup. These facts imply

$$
R\left(I_{1}\right) /\left(R\left(I_{1}\right) \cap R\left(I_{2}\right)\right)=0,
$$

consequently $R\left(I_{1}\right)=R\left(I_{1}\right) \cap R\left(I_{2}\right) \subseteq R\left(I_{2}\right)$ which means the desired monot-ony of $\varphi: I \rightarrow R(I)$.

Propositrion 2. If $I$ and $S \mid I$ are 2 -semisimple, then $S$ itself is 2 -semi-simple.

The proof is, using the first isomorphism theorem and the definition of $\Re$-semisimplicity, almost trivial.

REMARK 3. Hitherto we need not have used our assumption that every $\Re$-semisimple semigroup is strongly $\mathscr{R}$-semisimple.

In what follows we use the modularity of the lattice of all ideals of a. semigroup. In fact, this lattice is distributive, since it is a sublattice of the Boolean algebra of all subsets of $S$. On the other side the proof of Theorem 4 is similar to author's [14] proof, taking set theoretical unions instead of sums.

THEOREM 4. Let $R$ be a radical such that every $\Re$-semisimple semigroup is strongly 2 -semisimple and $I$ an arbitrary (twosided) ideal of the semigroup $S$. Then the mapping

$$
\varphi: I \rightarrow R(I)
$$

is a join-endomorphism of the lattice of all (twosided) ideals of $S$, i.e. we always. have

$$
\varphi\left(I_{1} \cup I_{2}\right)=R\left(I_{1} \cup I_{2}\right)=R\left(I_{1}\right) \cup R\left(I_{2}\right)=\varphi\left(I_{1}\right) \cup \varphi\left(I_{2}\right) .
$$

Proof. It is easier to prove, that the right side of (2) is contained on the left hand side of (2), since $I_{j} \subseteq I_{1} \cup I_{2}$ for $j=1$ and 2 by Proposition 1 implies. $R\left(I_{j}\right) \subseteq R\left(I_{1} \cup I_{2}\right)$ and therefore

$$
R\left(I_{1}\right) \cup R\left(I_{2}\right) \subseteq R\left(I_{1} \cup I_{2}\right),
$$


indeed. The opposite inclusion will be verified in more steps, namely we shall show that both of $\left(I_{1} \cup I_{2}\right) /\left(R\left(I_{1}\right) \cup I_{2}\right)$, and $\left(R\left(I_{1}\right) \cup I_{2}\right) /\left(R\left(I_{1}\right) \cup R\left(I_{2}\right)\right)$ are $\mathscr{R}$-semisimple Rees factor semigroups.

By $I_{1} \supseteq R\left(I_{1}\right)$ and by the modularity of the lattice of all ideals of $S$ one has

$$
I_{1} \cap\left(R\left(I_{1}\right) \cup I_{2}\right)=R\left(I_{1}\right) \cup\left(I_{1} \cap I_{2}\right) .
$$

Therefore $I_{1} /\left(I_{1} \cap\left(R\left(I_{1}\right) \cup I_{2}\right)\right)$ is isomorphic to a homomorphic image of the strongly $\mathscr{R}$-semisimple semigroup $I_{1} / R\left(I_{1}\right)$ which implies the $\mathscr{R}$-semisimplicity of $I_{1} /\left(I_{1} \cap\left(R\left(I_{1}\right) \cup I_{2}\right)\right)$, too. Now by $R\left(I_{1}\right) \subseteq I_{1}$ and by (3) the first isomorphism theorem yields

$$
\left.\left(I_{1} \cup I_{2}\right) /\left(R\left(I_{1}\right) \cup I_{2}\right)\right) \cong I_{1} /\left(I_{1} \cap\left(R\left(I_{1}\right) \cup I_{2}\right)\right),
$$

thus also $\left(I_{1} \cup I_{2}\right) /\left(R\left(I_{1}\right) \cup I_{2}\right)$ is $\mathscr{R}$-semisimple, as it has been pointed out previously.

Similarly $R\left(I_{2}\right) \subseteq I_{2}$ and the modularity of the lattice of all twosided ideals of $S$ imply

$$
I_{2} \cap\left(R\left(I_{1}\right) \cup R\left(I_{2}\right)\right)=R\left(I_{2}\right) \cup\left(I_{2} \cap R\left(I_{1}\right)\right) .
$$

Thus $I_{2} /\left(I_{2} \cap\left(R\left(I_{1}\right) \cup R\left(I_{2}\right)\right)\right)$ is $\mathscr{R}$-semisimple, since by (4) it is a homomorphic image of the strongly $\mathscr{R}$-semisimple Rees factor semigroup $I_{2} / R\left(I_{2}\right)$ :

By the first isomorphism theorem and by $R\left(I_{2}\right) \subseteq I_{2}$ we have

$$
\left(R\left(I_{1}\right) \cup I_{2}\right) /\left(R\left(I_{1}\right) \cup R\left(I_{2}\right)\right) \simeq I_{2} /\left(I_{2} \cap\left(R\left(I_{1}\right) \cup R\left(I_{2}\right)\right)\right)
$$

thus the left hand side of $(5)$ is $\mathscr{R}$-semisimple.

Now, by Proposition 2 and by the second isomorphism theorem (see D. REES [8]) it follows that $\left(I_{1} \cup I_{2}\right) /\left(R\left(I_{1}\right) \cup R\left(I_{2}\right)\right)$ is $\mathfrak{R}$-semisimple. But the $\mathscr{R}$-semisimplicity of $\left(I_{1} \cup I_{2}\right) /\left(R\left(I_{1}\right) \cup R\left(I_{2}\right)\right)$ and the first isomorphism theorem imply also the (nontrivial) inclusion:

$$
R\left(I_{1} \cup I_{2}\right) \subseteq R\left(I_{1}\right) \cup R\left(I_{2}\right)
$$

which yields at once also $R\left(I_{1} \cup I_{2}\right)=R\left(I_{1}\right) \cup R\left(I_{2}\right)$, indeed.

This completes the proof of Theorem 4 .

\section{REFERENCES}

[1] S. A. Amitsur, A general theory of radicals I, Amer. J. Math. 74 (1952), 774-786; II, Amer. J. Math. 76 (1954), 100-125; III, Amer. J. Math. 76 (1954), 126-136.

[2] J. Bosák, On radicals of semigroups, Mat. Casopis Sloven. Akad. Vied. 12 (1962)' $230-234$ (in Russian).

[3] A. H. CLIFFord, Semigroups without nilpotent ideals, Amer. J. Math. 71 (1949), $46-58$.

14] A. H. CLIFFORD and G. B. PReston, The algebraic theory of semigroups I, II, Providence, 1961 and 1967. 
[5] H. J. HoEHलKR, Structure of semigroups, Canad. J. Math. 18 (1966), 449-491.

[6] E. S. LJapIN, Semigroups, Moscow, 1960 (in Russian).

[7] J. LuH, On the concepts of radical of semigroup having kernel, Portugal. Math. 19 (1960), 189-198.

[8] D. Rews, On semigroups, Proc. Cambridge Philos. Soc. 36 (1940), 387-400.

[9] St. Schwarz, Zur Theorie der Hallogruppen, Sb. Prac Prírodovéd. Fak. Slov. Univ. Bratislava 6 (1943), 1-64 (in Slovakian).

[10] H. SEIDEL, UUber das Radikal einer Halbgruppe, Math. Nacirr. 29 (1965), 255-263.

[11] L. N. SHEVRIN, On general theory of semigroups, Mat. Sb. 53 (1961), 367-386 (in Russian).

[12] R. SHuLKA, On nilpotent elements, ideals and radicals of semigroups, Mat. Časopis Sloven. Akad. Vied.13 (1963), 209-222 (in Russian).

[13] F. SzÁsz, Radikalbegriffe für Halbgruppen mit Nullelement, die dem Jacobsonschen ringtheoretischen Radikal ähnlich sind, Math. Nachr. 34 (1967), 157-161.

[14] F. SzÁsz, Ein radikaltheoretischer Vereinigungsendomorphismus des Idealverbandes der Ringe, Ann. Univ. Sci. Budapest. Eötvös Sect. Math. 12 (1969), $73-75$.

[15] F. SzÁsz, On radicals of semigroups with zero I, Proc. Japan Acad. 46 (1970), $595-598$.

[16] F. SzÁsz, On hereditary radicals of semigroups with zero, Proc. Japan Acad.

[17] R. WIEGANDT, On the structure of lower radical semigroups, Csechoslovak Math.J. $22(1972), 1-6$.

(Received March 27, 1972)

MTA MATEMATIKAI KUTATÓ INTÉZETE

H-1053 BUDAPEST

REÁLTANODA U. $13-15$.

HUNGARY 